\title{
Primary Sensory Neurons Express a Shaker-like Potassium Channel Gene
}

\author{
Angeles B. Ribera and Duy-Ai Nguyen \\ Department of Physiology, University of Colorado Health Sciences Center, Denver, Colorado 80262
}

Developmentally regulated action potentials are a halimark of Rohon-Beard cells, a class of sensory neurons. In these neurons as well as other primary spinal neurons of Xenopus laevis, the functional differentiation of delayed-rectifier potassium current regulates the waveform of the action potential during the initial day of its appearance. Later, the acquisition of another voltage-dependent potassium current-the A current-plays a major role in regulating excitability. In order to understand the molecular basis of this functional differentiation, genes encoding voltage-dependent potassium currents expressed in the embryonic amphibian nervous system are being cloned. Here, we report the functional properties and developmental localization of a second Xenopus Shaker-like gene (Xenopus $\mathrm{K}_{\mathrm{v}} \mathbf{1 . 1}$; XSha1; GenBank accession number M94258) encoding a potassium current. Homology screening with the mouse gene MBK1 led to its isolation. Functional expression in oocytes identifies it as a delayed-rectifier current when assembled as a homooligomeric structure. Specific transcripts corresponding to XSha1 and to the previously cloned gene XSha2 are both detectable by RNase protection in RNA isolated from the embryonic nervous system. However, whole-mount in situ hybridization reveals the temporal pattern and cellular localization of XSha1 but not XSha2 mRNA, suggesting that the concentration of XSha2 transcripts in individual cells is lower than the threshold for detection by this method. Of particular interest, Rohon-Beard cells express XSha 1 mRNA. In addition, XSha1 mRNA is detected in several structures containing neural crest derivatives including spinal ganglia, the trigeminal ganglion, and branchial arches; its presence in motor nerves and lateral spinal tracts suggests that both CNS and PNS glia express the mRNA. The results are consistent with a role for XSha 1 in regulating electrical excitability in Rohon-Beard cells, neural crest derivatives, and glia.

[Key words: delayed rectifier potassium current, Xenopus embryo, Shaker gene, in situ hybridization, Rohon-Beard cells, neural crest]

\footnotetext{
Received Jan. 13, 1993; revised Mar. 15, 1993; accepted May 27, 1993.

We thank Alison Hofmann, Dick Kennedy, Janet Licber, and Gcorge Tarver for technical assistance; Beatriz Ferreiro for suggestions regarding in situ hybridization; Bruce Tempel for MBK1 DNA; Darcy Kelley and Leslie Fischer for a cDNA library; and Corinna Burger, Marie Cecchini, Alison Hofmann, and Susan Jones for comments and discussion. The nucleotide sequence reported in this article has the GenBank accession number M94258. D.-A.N. is a student in the Medical Scientist Training Program. A.B.R. is a Fellow in Neuroscience of the Klingenstein Foundation, and a Basil O'Connor Scholar of the March of Dimes Foundation. This work was supported by NIH Grants NS25217 and NS01531.

Correspondence should be addressed to Angeles B. Ribera, Department of Physiology, C-240, University of Colorado Health Sciences Center, Denver, CO 80262.

Copyright (C) 1993 Society for Neuroscience $0270-6474 / 93 / 134988-09 \$ 05.00 / 0$
}

The acquisition and further development of electrical excitability have been extensively studied in amphibian spinal neurons. The results indicate that electrical excitability is one of the first functions acquired by postmitotic neurons (Warner, 1973; Lamborghini, 1980). Action potentials are initially detected at the neural tube stage ( $22 \mathrm{hr}$ after fertilization) and are calcium dependent and of long duration (Baccaglini and Spitzer, 1977). These action potentials precede neurite extension by $2-$ $4 \mathrm{hr}$ and the appearance of chemosensitivity by 4-6 hr (Bixby and Spitzer, 1982, 1984; Taylor and Roberts, 1983).

During the following day in vivo and in vitro, the impulse matures to a brief sodium dependent spike (Spitzer and Lamborghini, 1976; Baccaglini and Spitzer, 1977). This program is expressed in a cell autonomous manner, since a neuron developing in the absence of other cells also exhibits a transient period of long duration impulses (Henderson and Spitzer, 1986). Thus, electrical excitability is not only an early acquired phenotype but one that continues to be modified as development proceeds.

Biophysical analysis of the voltage-dependent currents that underlie the action potential indicates that the transition in ionic dependence of the impulse is due primarily to the maturation of a delayed-rectifier potassium current $\left(I_{\mathrm{Kv}}\right.$; Barish, 1986; O'Dowd et al., 1988; Lockery and Spitzer, 1992). During this time the calcium current shows very little change, while the sodium current doubles in density. The delayed-rectifier potassium current, however, triples in density and its kinetics are accelerated (O'Dowd et al., 1988). Later, another voltage-dependent potassium current, the A current $\left(I_{\mathrm{KA}}\right)$, appears. Its contribution results in further shortening of the duration of the action potential leading to additional changes in excitability (Ribera and Spitzer, 1990).

What are the molecular events involved in encoding the early appearance of electrical excitability? What is the basis of its continued regulation during early neuronal development? Investigation of these questions requires probes for genes encoding the ion channels that underlie action potentials. Given that potassium channels are pivotal in regulating action potential wave form, our efforts have focused on these proteins. Here we report the cloning of a second Xenopus Shaker-like potassium channel gene, XSha1, that is expressed in the embryonic nervous system. Its expression pattern is similar in some respects to that of XSha2: it is detectable in RNA extracted from the embryonic brain, and expression in oocytes produces a delayed-rectifier potassium current. However, important differences are apparent. Notably, in situ hybridization reveals the tissue specific expression of XShal and shows that it is localized to a subset of primary spinal neurons (Rohon-Beard cells), whose action potentials and currents have been extensively studied both in culture and in situ. In addition, XSha 1 mRNA is found in neural 
crest derivatives and nerve tracts. These characteristics of XSha1 make it an ideal candidate for molecular analyses of the regulation of electrical excitability in developing spinal sensory and neural crest cells.

\section{Materials and Methods}

Animals. Embryos were produced by breeding pairs of adult Xenopus primed with human chorionic gonadotropin (U.S. Biochemicals) and staged according to Nieuwkoop and Faber (1967). In addition some embryos were obtained by in vitro fertilization using standard methods (Moon and Christian, 1989).

Isolation of Xenopus Shaker homolog, DNA sequencing, and analysis. Xenopus cDNA libraries were screened as previously described (Ribera, 1990). A partial clone was first isolated from a Xenopus tadpole brain nervous system $\lambda$ UNIZAPII cDNA library using the mouse MBK1 sequence as a probe (generously provided by Dr. Bruce Tempel, Columbia Univ.) for reduced stringency screening. This clone was then used to screen a Xenopus larynx $\lambda$ ZAPII cDNA library (generously provided by Dr. Darcy Kelley and Leslie Fisher, Univ. of WA) at high stringency. A clone containing the entire coding sequence within a $\sim 1.6$ kilobase (kb) insert was identified (Fig. 1).

The two Yenopus clones were identical in their region of overlap $(\sim 0.6$ kb). Double-stranded DNA was subjected to alkaline denaturation. Primers designed to give overlapping sequences were synthesized on an Applied Biosystems PCR-Mate. The majority of the sequence was clearly read from both strands. Standard chain termination reactions with dideoxy nucleotides were carried out (Sanger et al., 1977) and DNA was synthesized with Sequenase 2.0 (U.S. Biochemicals) in the presence of ${ }^{35}$ S labeled dATP (New England Nuclear). DNA sequences were read and entered into a computer using a GEL READER interface and software (CBS Scientific) and analyzed using DNASTAR software (Madison, WI).

Oocyte recording. The entire coding region of the XSha 1 potassium channel gene was cloned into the pSP64T expression vector (Melton et al., 1984). It was excised from the larynx cDNA phagemid by cutting the $5^{\prime}$ and $3^{\prime}$ flanking regions of the polylinker with Xbal and EcoRV. The fragment was blunt ended with Klenow, and cloned into pSP64T that had been cut with BglII and blunt ended to yield compatible ends. The resulting recombinant pSP64T was linearized with Xba1. Capped sense RNA was generated by in vitro transcription with SP6 RNA polymerase in the presence of rNTPs and cap analog (Boehringer-Mannheim). Oocytes were removed, defolliculated, and injected with 10-50 ng of RNA as described previously (Ribera, 1990). Currents were detectable $1.5 \mathrm{~d}$ after injection of XShal RNA, and recordings were generally carried out between 3 and $5 \mathrm{~d}$ postinjection.

Comparison of the current induced by XSha1 with the current recorded from Xenopus spinal neurons was of particular interest and thus the standard solution was that used to study the endogenous neuronal current (O'Dowd et al., 1988; Ribera and Spitzer, 1989, 1990): $80 \mathrm{~mm}$ $\mathrm{NaCl}, 3 \mathrm{~mm} \mathrm{KCl}, 5 \mathrm{~mm} \mathrm{MgCl}, 10 \mathrm{~mm} \mathrm{CoCl}_{2}, 5 \mathrm{~mm}$ HEPES, pH 7.4. As previously noted, the high concentrations of divalent cations in this solution interfered with determination of the potassium selectivity (O'Dowd et al., 1988; Ribera, 1990). In experiments designed to examine the potassium dependence of the XShal current the bath solution was more similar to a typical oocyte recording solution (oocyte solution): $88 \mathrm{~mm} \mathrm{NaCl} ; 1,3$, or $10 \mathrm{~mm} \mathrm{KCl}, 0.33 \mathrm{~mm} \mathrm{Ca}\left(\mathrm{NO}_{3}\right)_{2} ; 2.4 \mathrm{~mm} \mathrm{NaHCO}$; $0.82 \mathrm{~mm} \mathrm{MgSO}_{4}$; and $5 \mathrm{~mm} \mathrm{Na-HEPES,} \mathrm{pH} \mathrm{7.4.} \mathrm{In} \mathrm{some} \mathrm{cases,} \mathrm{potas-}$ sium selectivity was also examined in the standard solution to permit comparisons with the endogenous current.

Tetraethylammonium (TEA) sensitivity was examined by addition of either $1,1.5,3,15$, or $40 \mathrm{~mm}$ TEA to the recording solutions. Flectrodes were filled with $3 \mathrm{M} \mathrm{KCl}$ and had resistances ranging between 0.1 and $3 \mathrm{M} \Omega$. Voltage protocols and data analysis were accomplished with the pCLAMP suite of programs (Axon Instruments). Comparisons for endogenous current are from data presented in Ribera and Spitzer (1990) or S. M. Jones and A. B. Ribera (unpublished observations).

$R N A$ isolation and RNase protection. The guanidinium thiocyanate method (Chomczynski and Sacchi, 1987) was used to isolate RNA from isolated brains. Homogenization in $10 \mathrm{ml}$ of guanidinium buffer $(4 \mathrm{M}$ guanidinium thiocyanate, $25 \mathrm{~mm} \mathrm{Na-citrate,} \mathrm{pH} 7,0.5 \%$ sarcosyl, 0.1 м 2-mercaptoethanol) per gram of tissue was followed by phenol extraction, and precipitation in isopropanol.

The regions of XShal or XSha2 chosen as templates for probe synthesis were specific to each and contained $3^{\prime}$ untranslated sequences. In order to maximize the amount of $3^{\prime}$ untranslated region in the probes and thus their specificity, the brain library XShal clone was linearized with Sall. The transcribed RNA was 493 base pairs (bp) containing $\sim 30$ nucleotides of vector sequences. The XSha2 probe was that described previously (Ribera, 1990), 396 nucleotides in length of which $\sim 70$ represent vector sequences. The different sizes of the two probes permitted simultaneous use in each RNA sample. Short complementary ("antisense") radioactive riboprobes were generated and used as described previously (Ribera, 1990). EF- $1 \alpha$ (a constitutively ubiquitously expressed gene; Krieg et al., 1989) and N-CAM (neural-specific long cytoplasmic domain form; Kintner and Melton, 1987; kindly provided by Dr. Chris Kintner, Salk Inst.) probes were used to control for the amount of cellular RNA and neural tissue, respectively, in samples.

In situ hybridization. For whole-mount preparations, the nonradioactive detection method (Harland, 1991) was followed with minor modifications (Ferreiro et al., 1993). In order to generate a short probe that contained 3 ' untranslated sequences, the clone from the brain library was linearized at a unique Hpal site. A 362-nucleotide-long RNA probe that consisted essentially of untranslated sequences was synthesized in the presence of digoxigenin-labeled UTP (Boehringer-Mannheim). Both pigmentcd and albino cmbryos were fixed in MEMPFA (4\% paraformaldehyde, 0.1 м MOPS, pH 7.4, $1 \mathrm{mM} \mathrm{MgSO}_{4}, 2$ mM EGTA) for 12$15 \mathrm{hr}$ at $4^{\circ} \mathrm{C}$. Hybridization was carried out overnight. After incubation with antibody, washes were carried out over $\geq 24 \mathrm{hr}$ with a minimum of seven changes. The alkaline phosphatase reaction product was developed in the presence of chromogenic substrate for 8-30 hr.

Whole-mount embryos were either cleared in Murray's solution (2:1 benzyl benzoate: benzyl alcohol) or embedded in Eponate 12 (Pella), sectioned at $10-20 \mu \mathrm{m}$, and stained with Eosin (2-5 sec). Photography of whole-mounts and sections was done with Kodak Ektachrome 160T film using appropriate color filters.

\section{Results}

\section{Identification of a second Xenopus Shaker homolog}

A cDNA clone containing a portion of the XShal coding sequence was isolated from a Xenopus tadpolc ncrvous system cDNA library (Stratagene) on the basis of its homology to MBK1. This clone contained a $0.9 \mathrm{~kb}$ insert that had its $5^{\prime}$ end immediately preceding the $\mathrm{S} 4$ region and extended in the $3^{\prime} \mathrm{di}-$ rection 290 bp past the stop codon. This DNA was then used to screen a postmetamorphic Xenopus larynx cDNA library at high stringency. A single hybridizing clone was identified. DNA sequencing indicated that the entire coding region was contained within its $\sim 1.6 \mathrm{~kb}$ insert.

The predicted amino acid sequence has 489 residues and a molecular weight of $\sim 56 \mathrm{kD}$ (Fig. 1). It is identical to the clone isolated from the nervous system library over the region of overlap. Overall, this amphibian clone is most conserved with the mammalian sequences MBK1 and RCK1 (88\%; Fig. 2; Baumann et al., 1988; Tempel et al., 1988). The last 13 residues of XSha1, MBK1, and RCK1 are the same and distinguish them from other Shaker-like gene family members. The next highest identities, 75-77\%, are found between XSha 1 and either XSha2 or the mammalian MK2 and RBK2 peptides (McKinnon, 1989; Chandy et al., 1990; Ribera, 1990). Other regions of high homology include the domain thought to contribute to specificity of subunit assembly (residues 22-133; Li et al., 1992); SS1-2, which is thought to constitute the pore (amino acids 354-374; MacKinnon and Yellen, 1990; Hartmann et al., 1991; Yellen et al., 1991; Yool and Schwartz, 1991); and the six putative transmembrane domains (S1-S6). In view of these similarities, this Xenopus Shaker-like gene has been named XSha1 and $\mathrm{K}_{\mathrm{v}} 1.1$ of Xenopus according to the standard nomenclature (Chandy et al., 1991). Similar conclusions are drawn from parsimony analysis (G. Gutman, personal communication).

A region rich in basic and serine residues (amino acids 437 445), containing consensus sites for cAMP as well as protein 
$-2+1$

AA ATG ACC GTA ATC GCA GGG GAG AAT ATG GAC GAG ACC TCA GTA TTG CCC GGT CAC CCT CAG GAC AGC TAC CAT CCA GAC CAA GAT GAC CAC Met Thr Val lle Ala Gly Glu Asn Met Asp Glu Thr Ser Val Leu Pro Gly HIs Pro Gin Asp Ser Tyr his Pro Asp GIn Asp Asp HIs

GAA TGC TGT GAG AGG GTG GTC ATC AAT GTG TCC GGC CTA CGC TTC GAG ACC CAG CTT AAG ACT CTC GCT CAG TTC CCC AGC ACT CTG CTA 180 glu Cys Cys Giu Arg Val Val Ile Asn Val Ser Gly Leu Arg Phe Glu Thr GIn Leu Lys Thr Leu Ala Gin Phe Pro Ser Thr Leu Leu 60

GGG AAC CCC AAA AAA CGG ATG CGT TAC TTT GAC CCC CTG AGG AAC GAG TAC TTC TTT GAC CGA AAC CGT CCA AGT TTC GAT GCC ATA TTA 270 gly Asn Pro Lys Lys Arg Met Arg Tyr Phe Asp Pro Leu Arg Asn Glu Tyr Phe Phe Asp Arg Asn Arg Pro Ser Phe Asp Ala 1 le Leu 90

TAT TAC TAC CAG TCT CGG GGT CCA CTC CGG ACA CCT GTT AAT GTT CCA CTG GAC ATG TTC TCT GAG GAA ATC AAG TTT TAT GAG TTA CCG 360 Tyr Tyr Tyr Gin Ser Gly Gly Arg Leu Arg Arg Pro Val Asn Val Pro Leu Asp Met Phe Ser Glu Glu Ile Lys Phe Tyr Glu Leu Gly 120

GAA GAG GCC ATG GAG AAG TTT AGG GAG GAT GAG GGT TTC GTA AAG GAA GAG GAA CGC CCT CTG CCA GAT AAA GAG TTC CAA CGC CAG GTG 450 Glu Glu Ala Met Giu Lys Phe Arg Glu Asp Glu Gly Phe Val Lys Glu Glu glu Arg Pro Leu Pro Asp Lys Glu Phe Gin Arg Gin Val 150

TGG CTC TTG TTT GAG TTC CCC GAA AGC TCC GGC CCG GCC AGG ATC ATT GCC ATA ATA TCT GTG ATG GTC ATC CTT ATA TCA ATT GTT ATC 540 Trp Leu Leu Phe Glu Phe Pro Glu Ser Ser Gly Pro Ala Arg Ile lle Ala lle Ile Ser Val Met Val Ile Leu Ile Ser lle Val Ile IBo

TTC TGC TTG GAG ACT TTG CCA GAA TTA AAA GAT GAG CGG ATC TTC AGT CGA CGG GTG AAC AAC AGC ACA GTT TTC TAC AAA TCC AAC ATC 630 Phe Cys leu glu Thr leu Pro Glu leu lys Asp Glu Arg Ile Phe Ser arg arg Val Asn Asn Ser Thr Val Phe Tyr lys Ser Asn 1 le 210

TTC ACG GAT CCA TTC TTT GTG GTG GAG ACC CTC TGC ATT ATC TGG TTT TCC TTT GAA TTG GTG GTG AGG TTC TTT GCA TGT CCC AGC AAA 720 Phe Thr Asp Pro Phe Phe Val Val Glu Thr Leu Cys Ile Ile Trp Phe Ser Phe Glu leu Val Val Arg Phe Phe Ala Cys Pro Ser Lys 240

CCG GAA TTC TTT AAG AAC ATC ATG AAC TTC ATT GAC ATT GTG GCC ATC ATC CCT TAC TTT ATC ACC TTG GGG ACT GAA ATG GCA GAG CAA 810 Pro Glu Phe Phe Lys Asn Ile Met Asn Phe lle Asp lle Val Ala lle lle Pro Tyr Phe Ile Thr Leu Gly Thr Glu Met Ala Glu GIn 270

GAA GGT CCC CAA AAA GGA GAA CAG GCA ACA TCT TTG GCA ATC CTG AGG GTC ATC AGA CTG GTA AGA GTG TTT AGA ATC TTC AAA CTC TCC 9O0 Glu Gly Pro Gin Lys Gly Glu gin Ala Thr Ser Leu Ala lle Leu Arg Val lle Arg Leu Val Arg Val Phe Arg Ile Phe Lys Leu Ser 300

AGG CAT TCT AAG GGA CTC CAG ATT TTG GGA CAG ACC TTG AAA GCT AGC ATG AGA GAA TTA GGG TTG CTA ATT TTT TTT CTA TIC ATT GGG 990 Arg HIs Ser Lys Giy Leu GIn lle Leu Gly GIn Thr Leu Lys Ala Ser Met Arg Glu Leu Gly Leu Leu Ile Phe Phe Leu Phe 1 le Gly 330

GTC ATC TTG TTC TCC AGT GCA GTG TAC TTT GCT GAA GCT GAA GAG GAT GAA TCT CAT TTT ACA AGT ATC CCT GAT GCT TTC TGG TGG GCG 1080 Val lle Leu Phe Ser Ser Ala Val Tyr Phe Ala Glu Ala Glu glu Asp Glu Ser His Phe Thr Ser lle Pro Asp Ala Phe Trp Trp Ala 360

GIG GTA TCC ATG ACC ACT GTG GGC TAT GGT GAC ATG TAC CCT GTG ACA ATT GGA GGC AAA ATC GTG GGC TCC TTG TGT GCC ATC GCT GGT IITO Val Val Ser Met Thr Thr Val Gly Tyr Gly Asp Met Tyr Pro Val Thr lle Gly Gly Lys lle Val Gly Ser Leu Cys Ala Ile Ala Gly 360

GTG CTG ACA ATT GCC CTG CCT GTA CCT GTC ATC GTG TCC AAC TTC AAC TAC TTC TAC CAC CGA GAA ACT GAA GGG GAG GAA CAG GCT CAG 1260 Val Leu Thr Ile Ala leu Pro Val Pro Val lle Val Ser Asn Phe Asn Tyr Phe Tyr his Arg Glu Thr Giu Gly Glu Giu Gin Ala Gin 420

TTA CTC CAT GTT AGC TCC CCC AAT TTA GCC TCT AAC AGT GAT CTG AGT CGA CGA AGT TCC TCC GCA ATG AGC AAA TCT GAG TAC ATG GAG 1350 Leu leu His Val Ser Ser Pro Asn leu Ala Ser Asn Ser Asp Leu Ser Arg arg Ser Ser Ser Ala Met Ser Lys Ser GIu Tyr Met Glu 450

ATT GAA GAG GAT CTG AAT AAT AGC ATA GAT AAC TTT AGA GAG GCA AAT ATC AGA ACT GGC AAT TGC ACC ATA GCC AAT CAG AAC TGT GTT I440 lle Glu glu Asp Leu Asn Asn Ser Ile Asp Asn Phe Arg Giu Ala Asn Ile Arg Thr Gly Asn Cys Thr Ile Ala Asn Gin Asn Cys Vol 480

AAC AAA AGC AAG CTC CTG ACA GAT GTG TAG ACA CGA CAG TCC CAT TAC AGA ATT ATC ATG ACC ACT TCC CTC TTT GCA GGG CCA CCA TGA 1530 Asn Lys Sor Lys LOW LOW Thr Asp Val STOP

ACT TAA CCT TCA AAA ATA CAG AGG CCT AGT ACA AAT TAG GGG AGC AGC CCC

1581

Figure 1. Sequence of a Shaker homolog in Xenopus: nucleotide and predicted amino acid sequence of XSha 1. The three-letter code for amino acids is used.

kinase $\mathrm{C}$-dependent phosphorylation, is found near the carboxy terminus in a putative intracellular domain; this position is analogous to the location of a consensus sequence for cAMPdependent phosphorylation in mouse and fly Shaker-like sequences (e.g., Tempel et al., 1988). The possibility of protein kinase $\mathrm{C}$-dependent phosphorylation is particularly intriguing given the known developmental regulation of the kinetics of the endogenous delayed-rectifier current by a mechanism involving this enzyme (Desarmenien and Spitzer, 1991).

\section{XShal encodes a delayed-rectifier-type current}

Based upon the amino acid sequence, XShal is predicted to be a delayed-rectifier-type current since it does not contain an inactivating ball in the amino terminus region (Hoshi et al., 1990). Functional expression of XSha 1 verified this prediction. Capped sense transcripts were generated (Melton et al., 1984) and injected into Xenopus oocytes. The oocyte membrane was clamped at $-80 \mathrm{mV}$, and then stepped for $60 \mathrm{msec}$ intervals to depolarized potentials expected to activate potassium currents. This protocol demonstrated a voltage-activated current in 24 of 27 XSha1-injected oocytes (three batches of oocytes) that was not found in uninjected oocytes. The current was sustained during the $60 \mathrm{msec}$ voltage pulse (Fig. $3 A$ ), indicating that it is of the delayed-rectifier type. The average current amplitude induced by XShal was $6.8 \pm 1.1 \mu \mathrm{A}(+30 \mathrm{mV})$. Currents greater than $1.8 \mu \mathrm{A}(+30 \mathrm{mV})$ were never observed after expression of XSha2, even when fourfold greater concentrations of RNA were injected into oocytes.

Under recording conditions similar to those used to study the endogenous delayed rectifier, activation of the XShal current is observed at potentials positive to $-40 \mathrm{mV}$, which is more hyperpolarized than that observed for the endogenous current (O'Dowd et al., 1988; Ribera and Spitzer, 1989, 1990) or for XSha2 (Fig. 3B,C; Ribera, 1990). In this regard, XSha 2 is more similar to the endogenous current.

The ionic dependence of the XSha1 RNA induced current is strongly potassium selective. Elevating the external potassium concentration from 1 to $10 \mathrm{~mm}$ leads to a $60 \pm 2 \mathrm{mV}$ shift in the reversal potential of tail currents $(n=10)$. The Nernst equation predicts a $58 \mathrm{mV}$ shift for a purely potassium-dependent current. The data confirm the prediction and are consistent with results for mammalian homologs as well as the endogenous 
voltage-dependent potassium currents (O'Dowd et al., 1988; Christie et al., 1989; Stuhmer et al., 1989; Ribera and Spitzer, 1990).

Inspection of the putative pore sequence (amino acids 354 374 ; Figs. 1, 2) suggests that the potassium channel blocker TEA will strongly inhibit the current, given the tyrosinc residuc at position 373 (Stuhmer et al., 1989; MacKinnon and Yellen, 1990). In fact, at concentrations of $1.5 \mathrm{~mm}$ and $15 \mathrm{~mm}$ TEA, the current was reduced by $64 \pm 6 \%(n=8)$ and $88 \pm 2 \%(n$ $=13$ ) in oocyte solution (Fig. 4). However, in the presence of the standard solution, low concentrations of TEA were less effective. For example, $1.5 \mathrm{~mm}$ TEA in standard solution resulted in only an $18 \pm 6 \%(n=4)$ reduction of the current; at higher concentrations of TEA, the apparent competition between it and divalent cations was less pronounced. XSha2, with a valine at the analogous position, is expected to show low sensitivity to TEA on the basis of structure (Stuhmer et al., 1989; MacKinnon and Yellen, 1990). Extension of previous work showed that $40 \mathrm{~mm}$ TEA produced only $20 \%$ reduction of the XSha2-induced current expressed in oocytes (Fig. 4; Ribera, 1990).

Pharmacological agents distinguish among the various potassium currents that function within a single cell (e.g., Thompson, 1977; Wu and Barish, 1992). The endogenous delayedrectifier potassium current $\left(I_{\mathrm{Kv}}\right)$ is sensitive to external TEA, being reduced by $80 \%$ at a concentration of $40 \mathrm{~mm}$; at a similar concentration the endogenous A current $\left(I_{\mathrm{KA}}\right)$ is inhibited only by $20 \%$ (Fig. 4; Ribera and Spitzer, 1990). Thus, with respect to TEA sensitivity, the endogenous delayed-rectifier potassium current is more similar to XSha1 than it is to XSha2.

\section{XShal is expressed in the nervous system}

Potassium channels are expressed in a wide variety of tissues (see Ribera and Spitzer, 1992, for review). In order to determine whether XShal might contribute to the formation of neuronal potassium channels, its presence in neural tissue was first determined by the sensitive method of RNase protection, as done previously (Ribera, 1990). Further, to compare XShal levels to those of XSha2, probes for both were simultaneously included in the hybridization reaction. In RNA extracted from tadpole brains, both XShal and XSha2 mRNA are detectable (Fig. 5). The autoradiographic signals are similar, suggesting that the levels of the two mRNAs in whole-brain extracts are comparable.

\section{In situ hybridization indicates that XShal is expressed in both the CNS and PNS}

The cellular distribution of XSha1 expression was addressed using whole-mount in situ hybridization. For 1-3 d embryos, a whole-mount consists of the entire embryo. Visualization quickly locates the hybridization signal to specific regions or tissues of the embryo. Subsequently, the embryo can be sectioned to examine more precisely the distribution of the mRNA.

XSha1 mRNA has an unusual pattern of expression. In 3-dold embryos, XSha1 mRNA is specifically detected in the head and throughout the length of the embryo in the dorsal side (Fig. $6 a$ ). Thus, XShal expression predominates in the nervous system. However, the gills (Fig. $6 b$ ) also show an intense signal. Of particular interest is the signal that is seen throughout the dorsal aspect of the spinal cord (Fig. 6c). As shown in more detail in Figures 7 and 8 , this signal is due to expression in Rohon-Beard neurons.

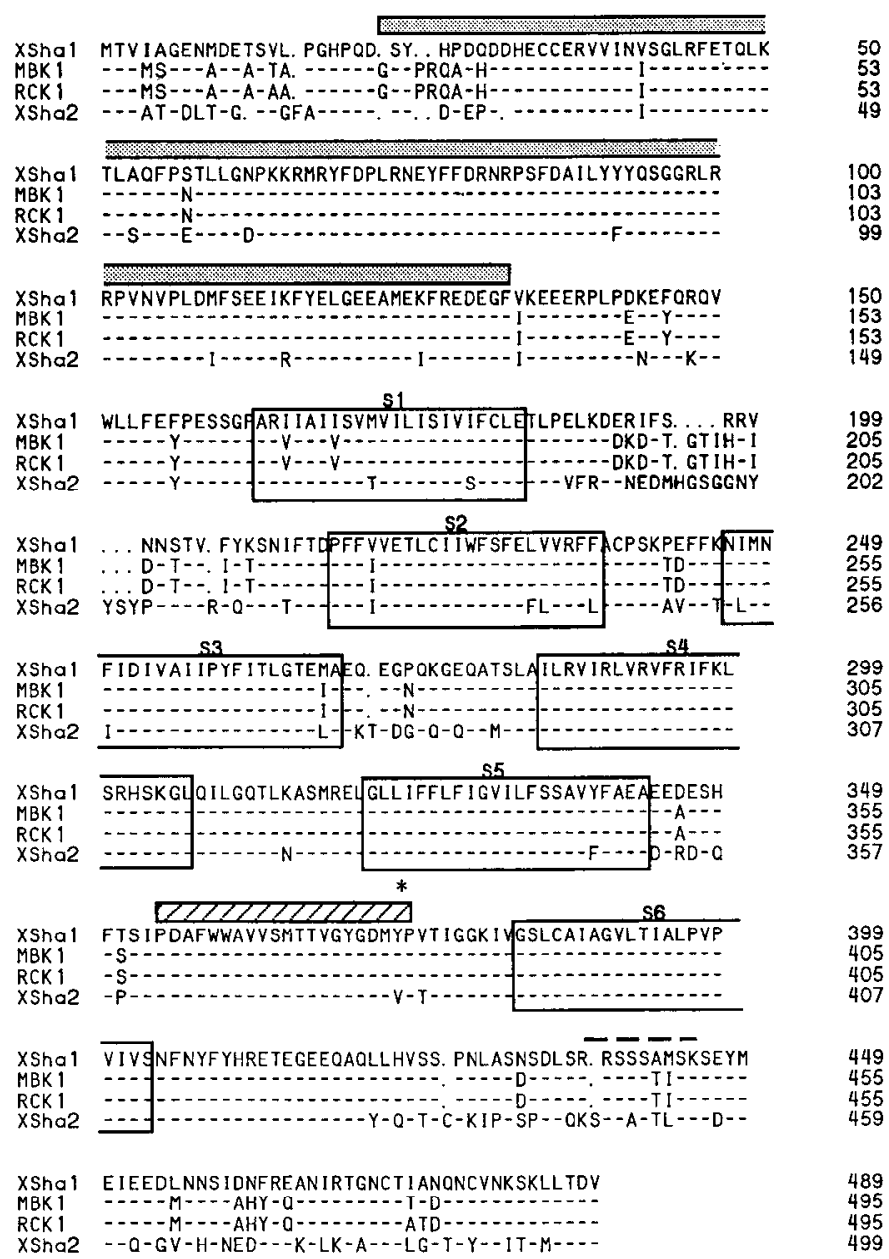

Figure 2. Alignment of the XSha I, XSha2, MBKI, and RCK1 peptides. XSha 1 shares $89 \%$ identity with MBK1 and RCK1 (Tempel et al., 1988; Stuhmer et al., 1989) but only $77 \%$ identity with XSha2, a previously cloned Xenopus Shaker gene (Ribera, 1990). Identity with XShal is indicated by dashes; gaps that were introduced to enhance the alignment are indicated by dots. The one-letter amino acid code is used. Unique features of the $\mathrm{K}_{\mathrm{v}} 1.1$ Shaker genes include the carboxy-terminal residues and the tyrosine at position 373 . The region thought to specify subunit assembly specificity (shaded bar) extends from amino acids 22 to 133 and $94 \%$ and $89 \%$ identical to the similar region in MBK 1/RCK1 and XSha2, respectively. The putative transmembrane domains $S 1-S 6$ are drawn into boxes. The putative pore (hatched bar, residues 354 $374)$ contains the tyrosine residue $(373$, asterisk) implicated in determination of TEA sensitivity. Consensus sites for cAMP-dependent protein kinase $\mathrm{C}$ phosphorylation are found near the carboxy terminus in the region indicated by a dashed line (residues 437-445). Alignment was achieved using the MEGALIGN program (DNASTAR) followed by adjustments done by eye. MBK 1 and RCK 1 sequences were downloaded from the GenBank/EMBL database.

The neural structures exhibiting XShal are better defined in sections. At the level of the eye (Fig. $7 a, d$ ), the trigeminal ganglion presents a robust reaction product. The signal in the eye was also found in control embryos, and thus not specific. At the levels of the hindbrain and spinal cord (Fig. 7b,c) Rohon-Beard cells and lateral tracts present the signal. In the trunk region, at repeated intervals, sections show an XSha 1 signal in the location of condensing spinal ganglia (Fig. $7 \mathrm{C}$ ). In a longitudinal view, at the level of the notochord, the reaction product is observed in the intermyotomal junction region (Fig. 7e). The motor nerves run into the junction at this level (Chu and Klymkowsky, 1989; Hemmati-Brivanlou et al., 1992); the staining may reflect the 

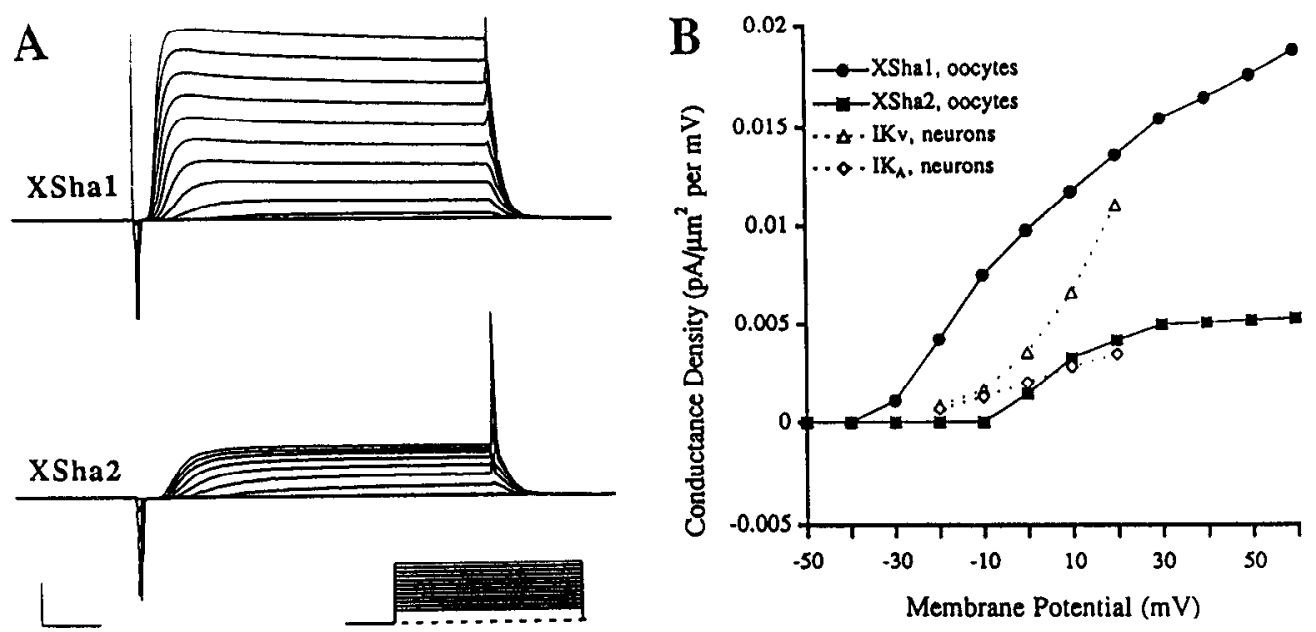

Figure 3. Characterization of the voltage-dependent potassium current induced by XShal transcripts. $A$, Currents induced by expression of XSha 1 (top) or XSha2 (bottom) RNA in oocytes were elicited by depolarizing steps to voltage levels ranging between -50 to $+60 \mathrm{mV}$ from a holding potential of -80 . The XShal-induced current begins to activate at $-40 \mathrm{mV}$ and is sustained for the duration of the $60 \mathrm{msec}$ pulse, indicating that is a delayed-rectifier-like current. XSha2 RNA induces a delayed-rectifier potassium current, which has a voltage dependence of activation that is depolarized with respect to XSha1. Calibration: $2 \mu \mathrm{A}, 10 \mathrm{msec}$. $B$, Conductance density-voltage plots compare the voltage dependence of activation of XSha 1- and XSha2-induced currents in oocytes to that of the endogenous delayed rectifier $\left(I_{\mathrm{Kv}}\right)$ and A potassium currents $\left(I_{\mathrm{KA}}\right)$ recorded from primary spinal neurons (after Ribera and Spitzer 1989, 1990). Oocyte current densities were calculated assuming a cell diameter of $1 \mathrm{~mm}$. The endogenous delayed-rectifier current has activation properties that are more similar to that of XSha2. Recordings were done in standard solution.

presence of XSha 1 in the Schwann cells that ensheath the motor nerve. These data indicate that XShal expression is found in a subset of CNS and PNS structures.

In addition, XSha1 is found in a non-neural tissue, the gill arches (Figs. $6 b, 7 f$ ). The gills arise from the branchial arches,

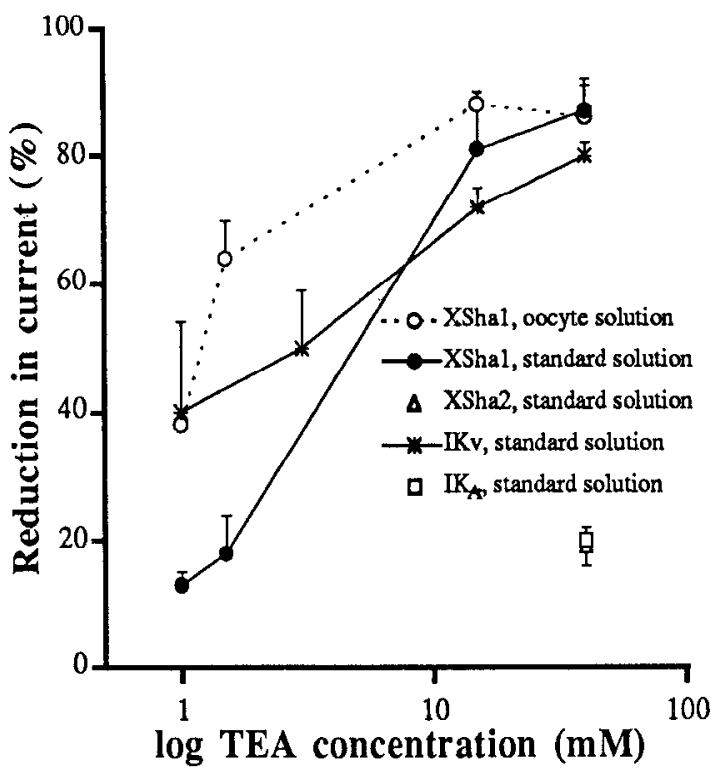

Figure 4. TEA sensitivity of XShal-induced current in oocytes. The current is efficiently blocked by TEA, in particular in the presence of oocyte buffer. In the presence of the standard solution, which contains $10 \mathrm{~mm}$ cobalt and $5 \mathrm{~mm}$ magnesium, TEA sensitivity is reduced at low concentrations ( 1 and $1.5 \mathrm{~mm}$ ) but not at higher concentrations ( 15 and $40 \mathrm{~mm}$ ). The sensitivities of the XSha2-induced current in oocytes as well as the endogenous delayed-rectifier $\left(I_{\mathrm{KV}}\right)$ and A currents $\left(I_{\mathrm{KA}}\right)$ to 40 mM TEA in standard solution are also shown. Data for the endogenous currents are obtained either from Ribera and Spitzer (1990) or from S. M. Jones and A. B. Ribera (unpublished observations). Data are presented as mean \pm SEM for three to eight oocytes or neurons. a neural crest derivative. In fact, the majority of the neural presence of XShal is localized to neural crest derivatives.

Two aspects of XShal expression differed in 2 versus $3 \mathrm{~d}$ embryos. The first reflected the more medial position of the Rohon-Beard cells in 3 versus $2 \mathrm{~d}$ embryos. For example, these cells are found in a dorsal lateral position in a section from a 2 $\mathrm{d}$ embryo at the level of the spinal cord (Fig. 7c), whereas in a section from a $3 \mathrm{~d}$ embryo, the cells have a more medial location (Fig. 8a). This difference is also detectable at the level of the whole-mount by optically sectioning the specimen (Fig. $8 c, e$ ). Second, the presence of superficial tracts that run dorsoventrally in repeated fashion is apparent only in $3 \mathrm{~d}$ embryos. The tracts follow the pattern cxpected for motor nerves (Fig. $8 c-h$; see also Fig. 7e; Chu and Klymkowsky, 1989; Hemmati-Brivanlou et al., 1992), and may reflect the presence of XShal in the neural crest derivatives forming peripheral glia, Schwann cells (Fig. 8eh). In a $2 \mathrm{~d}$ embryo, neural crest cells are migrating (Sadaghiani and Thiebaud, 1987; Krotoski et al., 1988) and thus may have a more internal location (Fig. $8 c, d$ ).

\section{Discussion}

We find that a variety of structures containing neural crest derivatives express a Xenopus Shaker-like gene, XShal. The pattern includes such diverse tissues as the trigeminal and spinal ganglia and the branchial arches; several nerve tracts also show XSha 1 mRNA, suggesting that it may be in glia. The restriction of XSha I mRNA to numerous structures containing neural crest derivatives supports the idea that it is the crest derivatives rather than other cells (e.g., placodal cells in the trigeminal ganglion) that express the transcript.

Of particular interest is the detection of the mRNA in RohonBeard cells, for which the development of electrical excitability has been extensively studied. However, these cells are not widely considered to be neural crest derivatives (Jacobson, 1991), although they are found in the region of the neural tube most proximate to the neural crest (Sadaghiani and Thiebaud, 1987; 
Hartenstein, 1989; Eagleson and Harris, 1990). The presence of XShal in Rohon-Beard cells may reflect a shared lineage with the neural crest.

XShal mRNA demonstrates novel distributions. First, its appearance in gill arches suggests that it may be in cartilage cells, the expected neural crest derivative in this location. Expression of potassium channels in these cells is hard to reconcile with an expected role in determining excitability, although the broad roles of ion channels are increasingly appreciated (Ribera and Spitzer, 1992, for review). Second, the clone was isolated from a larynx cDNA library. Its presence in muscle contrasts with the pattern observed here. The larynx was isolated from older animals and could reflect developmental changes in the distribution of the mRNA. Alternatively, since XShal mRNA was present in several nerve tracts and the larynx was not denervated, the presence of the XShal clone may reflect RNAs found in the innervating nerve fibers.

The majority of the in situ hybridization data were obtained from albino specimens to avoid the signal due to pigmentation. However, physiological analyses of the endogenous potassium currents expressed in Xenopus spinal neurons have been done using cultures prepared from pigmented embryos. We found that the distribution of XShal mRNA was the same in pigmented and albino embryos (Figs. 7, 8).

The development of potassium currents and electrical excitability in neural crest derivatives has been studied in avian and mammalian systems (Bader et al., 1985; Belluzzi et al., 1985; Nerbonne and Gurney, 1989; McFarlane and Cooper, 1992). Both delayed-rectifier and $\mathrm{A}$ potassium currents function in these cells. Although no single pattern emerges, the densities and other properties of these potassium currents are developmentally regulated (see Ribera and Spitzer, 1992, for review). Since the exact schedule followed requires specific examination in each system, neural crest-derived cells do not have a universal program for the functional expression of excitability.

Functional expression of XShal in oocytes induces a delayedrectifier-type potassium current resembling that studied in Xenopus spinal neurons both in culture and in vivo with respect to properties of inactivation, TEA sensitivity, and potassium selectivity (Harris et al., 1988; O'Dowd et al., 1988; Ribera and Spitzer, 1990; Desarmenien et al., 1993). However, the voltage dependence of activation is considerably different and is more reminiscent of the endogenous A current, which has a less steep voltage dependence of activation with respect to the delayed rectifier (Fig. 3; Ribera and Spitzer, 1990). XShal mRNA was not apparent in Rohon-Beard cells until $2 \mathrm{~d}$ of development. This is later than would be expected if it participated in forming the endogenous delayed-rectifier current, but is consistent with a contribution to the endogenous A current. If so, this would require that XShal peptides form heteromeric structures with other Shaker-like peptides that have an inactivating ball (Christie et al., 1990; Hoshi et al., 1990; Isacoff et al., 1990; Ruppersberg et al., 1990).

Several issues are important to consider when drawing comparisons between natively expressed currents and those induced in the oocyte by expression of injected RNA. First, XShal peptides expressed in oocytes and in neurons may undergo different extents of posttranslational processing. Second, endogenous subunits may combine with other Shaker-like subunits to form heteromultimeric channels with novel properties (Christie et al., 1990; Isacoff et al., 1990; Ruppersberg et al., 1990). Third, potassium channels may share common associated subunits as

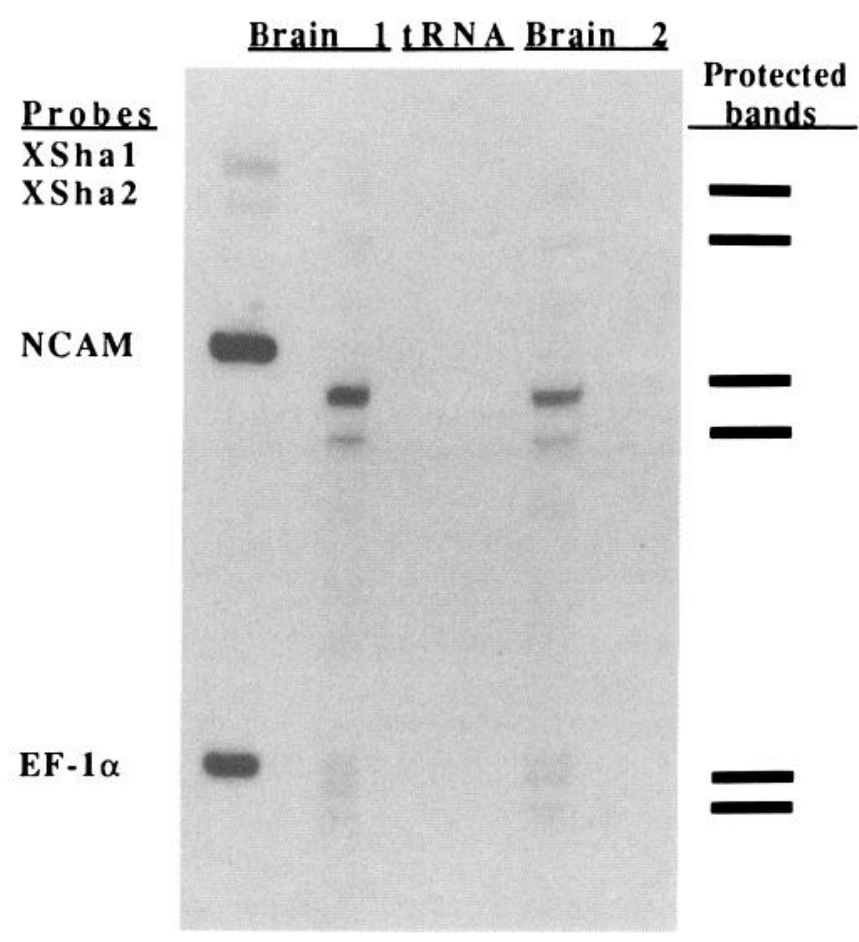

Figure 5. Relative levels of XSha 1 and XSha2 mRNA in tadpole brain RNA. RNase protection assay indicates that XShal is expressed in the brain of 2-3-week-old embryos at levels comparable to that of XSha2. The results for two different brain RNA preparations are shown. A neural-specific N-CAM probe, an early marker of neural induction (Kintner and Melton, 1987), is used to assess the relative amounts of neural tissue in the samples. EF- $1 \alpha$ protection is presented to indicate the relative amounts of total RNA that were incubated with the probes. The $t R N A$ lane demonstrates that incubation with nonhybridizing tRNA does not protect the probes from degradation and that signals are due to true protection from digestion. Note that the protected bands run slightly faster than the full-length probe, since the probe contains vector sequences at its $3^{\prime}$ and $5^{\prime}$ ends that will not hybridize to the extracted RNA.

demonstrated by analysis of potassium currents in larval muscle of ether a go-go mutants (Zhong and $\mathrm{Wu}, 1991$ ).

XSha 1 is consistently detectable in 2 and $3 \mathrm{~d}$ embryos. XSha 1 transcripts are not detected in younger embryos, although the method of in situ hybridization is sufficiently sensitive to detect low-abundance mRNAs, such as En-2 (Harland, 1991; Hemmati-Brivanlou et al., 1991). At 2-3 d, several neural cells derived from the crest have reached their characteristic position and are beginning to undergo final differentiation (Sadaghiani and Thiebaud, 1987; Krotoski et al., 1988). For example, functional innervation of the head by trigeminal neurons is detectable in a $2 \mathrm{~d}$ embryo (stage 33; Davies et al., 1982); a potassium A current functions in Rohon-Beard neurons at this time (Ribera and Spitzer, 1990). Activation of ion channel genes may characterize terminal differentiation in these cells.

The previously cloned gene XSha2 showed highest identity to the mammalian $\mathrm{K}_{\mathrm{v}} 1.2$ genes (MBK2, RBK2, RCK5; McKinnon, 1989; Stuhmer et al., 1989; Chandy et al., 1990). However, reconstruction of phylogenetic trees places it outside the mammalian group, and calls into question assignment of XSha 2 as the Xenopus homolog of $\mathrm{K}_{\mathrm{v}} 1.2$ (Strong et al., 1993). The finding that this second Xenopus gene, XShal, is more similar to mammalian $\mathrm{K}_{\mathrm{v}} 1.1$ genes rather than to XSha2 supports assignment of XShal and XSha 2 as $\mathrm{K}_{\mathrm{v}} 1.1$ and $\mathrm{K}_{\mathrm{v}} 1.2$ of Xenopus, 

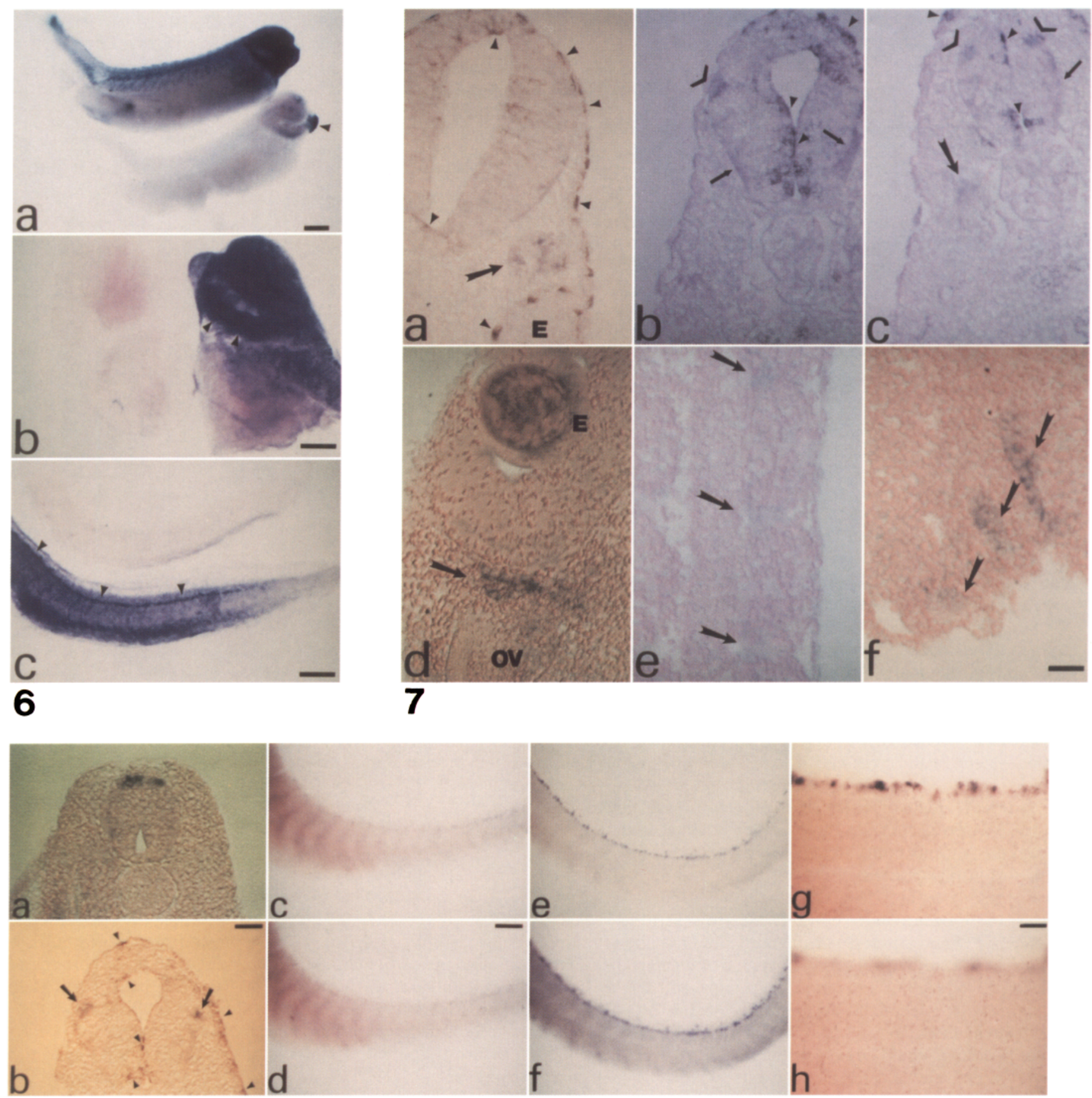

8

Figure 6. XShal transcripts are detectable in young embryos by whole-mount in situ hybridization. Embryos were incubated as whole-mounts with sense control or antisense XShal probes. The RNA probes were labeled with digoxigenin (Boehringer-Mannheim), which permitted detection of hybridization with anti-digoxigenin antibodies coupled to alkaline phosphatase followed by reaction with the substrates NBT/BCIP to form the purple precipitate. $a$, XShal hybridization signal is localized to the nervous system. Three day embryos [Nieuwkoop and Faber (NF) stage 40] hybridized either to antisense XShal probe (top) or sense control probe (bottom) were processed similarly. Note the intense staining in the head, dorsal and ventrolateral aspects of the spinal cord. Occasionally in controls, the cement gland (arrowhead) showed background staining. However, in the control of $b$, the cement gland does not show background staining. This difference may be due to the time the embryos are in substrate solution ( $30 \mathrm{hr}$ in $a$ vs. $20 \mathrm{hr}$ in $b$ and $c$; see Materials and Methods). $b$ and $c$, Slightly older embryos (NF stage 42) hybridized to antisense XShal probes $(b$, right, and $c$, bottom) or sense control probes $(b$, left, and $c$, top) and examined at higher power demonstrate further the specificity of the XShal signal. $b$, In the head, both the brain and the gill area (arrowheads) show intense staining. $c$, Along the length of the spinal cord, the dorsal aspect (arrowheads) contains XShal mRNA. Scale bars, $a, 700 \mu \mathrm{m} ; b$ and $c, 1 \mathrm{~mm}$.

Figure 7. XShal is detected in several neural tissues, many of which contain neural crest derivatives. $a-c$, Transverse sections through pigmented embryos (NF stage 38/39) at the level of the forebrain (a), hindbrain (b), and spinal cord (c). The brown-black staining in a-c is due to pigment 
respectively. However, the absence of a glycine, a proline, and an arginine residue at the beginning of the region associated with subunit assembly (Fig. 2) is a feature specific to the Xenopus peptides. Resolution of the evolutionary origins of these channels will be aided by a larger data set acquired as more Xenopus sequences are cloned. Preliminary examination of a more recent and larger data base by parsimony analysis does indeed indicate that XSha 1 and XSha 2 cluster with the mammalian $K_{v} 1.1$ and $\mathrm{K}_{\mathrm{v}} 1.2$ genes, respectively (G. Gutman, personal communication).

Analysis of several potassium channel mRNAs indicates that each shows a specific tissue distribution and developmental regulation (McKinnon, 1989; Beckh and Pongs, 1990; Swanson et al., 1990; Drewe et al., 1992; Hwang et al., 1992; Perney et al., 1992; Rudy et al., 1992; Tsaur et al., 1992). How does the pattern of mammalian $\mathrm{K}_{\mathrm{v}} 1.1$ mRNA expression compare to that of XSha1? In rat, in situ hybridization studies demonstrate that $\mathrm{K}_{\mathrm{v}} 1.1 \mathrm{mRNA}$ is limited to the nervous system, and that its levels are highest in the adult and not detected in the embryo, although $\mathrm{K}_{\mathrm{v}} 1.3$ and $\mathrm{K}_{\mathrm{v}} 1.4 \mathrm{mRNAs}$ are present (Beckh and Pongs, 1990). In the brain, $K_{v} 1.1$ mRNA is found in several areas including the hippocampus, thalamus, cerebral cortex, and cerebellum (Tsaur et al., 1992). Its distribution overlaps with but is distinct from that of $\mathrm{K}_{\mathrm{v}} 1.2$ mRNA. With respect to ncural crest derivatives, all peripheral nervous tissues examined express $\mathrm{K}_{\mathrm{v}} 1.1$ mRNA (Beckh and Pongs, 1990).

The roles of XShal remain to be further elucidated. The developmental program of excitability in Rohon-Beard cells is only partially accounted for by the properties of XShal. The functional differentiation of potassium currents in trigeminal neurons, spinal ganglia, and Schwann cells has not yet been studied, and it is not possible to relate their expression of XShal mRNA to specific cellular properties. Several studies indicate that different voltage-dependent potassium channel gene subfamilies function independently within cells (Baker and Salkoff, 1990; Covarrubias et al., 1991; Furukawa et al., 1992). Further, within a cell transcripts have specific subcellular localizations (Sheng et al., 1992). Thus, molecular definition of the events directing functional differentiation of potassium currents requires the identification of other Shaker- as wcll as Shab-, Shaw-, and Shal-like genes (Butler et al., 1989) expressed in the embryonic Xenopus nervous system.

\section{References}

Baccaglini PI, Spitzer NC (1977) Developmental changes in the inward current of the action potential of Rohon-Beard neurones. J Physiol (Lond) 271:93-117.
Bader CR, Bertrand D, Dupin E (1985) Voltage-dependent potassium currents in developing neurones from quail mesencephalic neural crest. J Physiol (Lond) 366:129-151.

Baker K, Salkoff L (1990) The Drosophila Shaker genc codes for a distinctive $\mathrm{K}^{+}$current in a subset of neurons. Neuron 2:129-140.

Barish ME (1986) Differentiation of voltage-gated potassium current and modulation of excitability in cultured amphibian spinal neurones. J Physiol (Lond) 375:229-250.

Baumann A, Grupe A, Ackermann A, Pongs O (1988) Structure of the voltage-dependent potassium channel is highly conserved from Drosophila to vertebrate central nervous systems. EMBO J 7:24572463.

Beckh S, Pongs O (1990) Members of the RCK family are differentially expressed in the rat nervous system. EMBO J 9:777-782.

Belluzzi O, Sacchi O, Wanke E (1985) A fast transient outward current in the rat sympathetic neurone studied under voltage-clamp conditions. J Physiol (Lond) 358:91-109.

Bixby JL, Spitzer NC (1982) The appearance and development of chemosensitivity in Rohon-Beard neurones of the Xenopus spinal cord. J Physiol (Lond) 330:513-536.

Bixby JL, Spitzer NC (1984) The appearance and development of neurotransmitter sensitivity in Xenopus embryonic spinal neurones. J Physiol (Lond) 353:143-155.

Butler A, Wei A, Baker K, Salkoff L (1989) A family of putative potassium channel genes in Drosophila. Science 243:943-947.

Chandy KG, Williams CB, Spencer RH, Aguilar BA, Ghanshani S, Tempel BL, Gutman GA (1990) A family of three mouse potassium channel genes with intronless coding regions. Science 247:973-975.

Chandy KG, Douglass J, Gutman GA, Jan L, Joho R, Kaczmarek L, McKinnon D, North RA, Numa S, Phillipson L, Ribera AB, Rudy B, Salkoff L, Swanson R, Steiner D, Tanouye M, Tempel BL (1991) Simplified gene nomenclature. Nature 352:26.

Chomczynski P, Sacchi N (1987) Single-step method of RNA isolation by acid guanadinium thiocyanate-phenol-chloroform extraction. Anal Biochem 162:156-159.

Christie MJ, Adelman JP, Douglass J, North RA (1989) Expression of a cloned rat brain potassium channel in Xenopus oocytes. Science 244:221-224.

Christie MJ, North RA, Osborne PB, Douglass J, Adelman JP (1990) Heteropolymeric potassium channels expressed in Xenopus oocytes from cloned subunits. Neuron 3:405-411.

Chu DTW, Klymkowsky MW (1989) The appearance of acetylated $\alpha$-tubulin during early development and cellular differentiation in Xenopus. Dev Biol 136:104-117.

Covarrubias M, Wei A, Salkoff L (1991) Shaker, Shal, Shab and Shaw express independent $\mathrm{K}^{+}$current systems. Neuron 7:763-773.

Davies SN, Kitson DL, Roberts A (1982) The development of the peripheral trigeminal innervation in Xenopus embryos. J Embryol Exp Morphol 70:215-224.

Desarmenien M, Spitzer NC (1991) Role of calcium and protein kinase $\mathrm{C}$ in development of the delayed rectifier potassium current in Xenopus spinal neurons. Neuron 7:797-805.

Desarmenien MG, Clendening B, Spitzer NC (1993) In vivo development of voltage-dependent ionic currents in embryonic Xenopus spinal neurons. J Neurosci 13:2575-2581.

Drewe JA, Verma S, Frech G, Joho RH (1992) Distinct spatial and

\footnotetext{
(arrowheads), which is typically found in the skin, the lining of the spinal canal and brain ventricles, and the gut epithelia. $a$, The trigeminal ganglion (arrow) contains XSha1 mRNA. b, Rohon-Beard cognates (carats) and lateral tracts (arrows) contain XSha $1 \mathrm{mRNA}$. , In a $2 \mathrm{~d}$ embryo, the RohonBeard neurons (carats) have a slightly lateral position. Lateral tracts (thin arrow) in the spinal cord contain XShal RNA. A spinal ganglion (thick arrow) that is beginning to condense shows the XShal signal. $d-f$, Longitudinal sections at the level of the eye and otic vesicle $(d)$, spinal cord and myotomes $(e)$, and gill arches $(f)$ of albino embryos (NF stage 40$)$. $d$, The trigeminal ganglion (arrow) is positive for XSha 1 as seen in a transverse section $(a) . e$, The region surrounding the myotomal junctions has XShal staining. Anterior is toward the bottom. $f$, The gill (branchial) arches present the XShal signal. Anterior is toward the left. $E$, eye; $O V$, otic vesicle. Scale bar, $200 \mu \mathrm{m}$.

Figure 8. XShal mRNA is localized to Rohon-Beard cells in the spinal cord and their cognates in the hindbrain. $a$, XShal is found in RohonBeard neuron cell bodies that line the dorsal midline of the spinal cord of a stage 40 albino embryo. $b$, At the level of the hindbrain, Rohon-Beard like cells (arrows) show XShal mRNA in a stage 38 pigmented embryo. As in Figure 7, the pigment (arrowheads) appears brown. $c$ and $d$, A lateral view of a stage 33 whole-mount albino embryo that was optically sectioned either at a midlevel (c) to focus on the Rohon-Beard cells, or at a more superficial level. $d$, Note that the repeated banding appears equally well in either plane of focus. $e$ and $f$, A lateral view of a stage 42 wholc-mount albino embryo that was optically sectioned either at a midlevel $(e)$ to focus on the Rohon-Beard cells, or at a more superficial level $(f)$. Note that the repeated banding appears faint at a midlevel $(e)$, but is more clear at a superficial level $(f) . g$ and $h$, Similar to $e$ and $f$, viewed at higher power. In $g$, note the Rohon-Beard cell bodies, whereas in $h$, note the superficial labeling that appears as repeating dorsoventral tracts. Scale bars: $a, b, g$, and $h, 200 \mu \mathrm{m} ; c-f, 500 \mu \mathrm{m}$.
} 
temporal expression patterns of $\mathrm{K}^{+}$channel mRNAs from different subfamilies. J Neurosci 12:538-548.

Eagleson GW, Harris WA (1990) Mapping of the presumptive brain regions in the neural plate of Xenopus laevis. J Neurobiol 21:427440.

Ferreiro B, Skoglund P, Bailey A, Dorsky R, Harris WA (1993) XASH 1 , Xenopus homolog of Acheate-Scute: a proneural gene expressed in anterior regions of the vertebrate central nervous system. Mech Dev 40:25-36.

Furukawa Y, Kandel ER, Pfaffinger P (1992) Three types of early potassium currents in Aplysia neurons. J Neurosci 12:989-1000.

Harland R (1991) In situ hybridization: an improved whole-mount method for Xenopus embryos. In: Methods in cell biology, Vol 36, Xenopus laevis (Kay B, Peng B, eds), pp 685-695. San Diego: Academic.

Harris GL, Henderson LP, Spitzer NC (1988) Changes in densities and kinetics of delayed rectifier potassium channels during neuronal differentiation. Neuron 1:739-750.

Hartenstein V (1989) Early neurogenesis in Xenopus: the spatio-temporal pattern of proliferation and cell lineages in the embryonic spinal cord. Neuron 3:399-411.

Hartmann HA, Kirsch GE, Drewe JA, Taglialatela M, Joho RH, Brown AM (1991) Exchange of conduction pathways between two related $\mathrm{K}^{+}$channels. Science 251:942-944.

Hemmati-Brivanlou A, de la Torre JR, Holt C, Harland RM (1991) Cephalic expression and molecular characterization of Xenopus En2. Development 111:715-724.

Hemmati-Brivanlou A, Mann RW, Harland RM (1992) A protein expressed in the growth cones of embryonic vertebrate neurons defines a new class of intermediate filament protein. Neuron 9:417-428.

Henderson LP, Spitzer NC (1986) Autonomous early differentiation of neurons and muscle cells in single cell cultures. Dev Biol 113:381387.

Hoshi T, Zagotta WN, Aldrich RW (1990) Biophysical and molecular mechanisms of Shaker potassium channel inactivation. Science 250: 533-538.

Hwang PM, Glatt CE, Bredt DS, Yellen G, Snyder SH (1992) A novel $\mathrm{K}^{+}$channel with unique localizations in mammalian brain: molecular cloning and characterization. Neuron 8:473-481.

Isacoff EY, Jan YN, Jan LY (1990) Evidence for the formation of heteromultimeric potassium channels in Xenopus oocytes. Nature 345:530-534.

Jacobson M (1991) Developmental neurobiology. New York: Plenum.

Kintner CR, Melton DA (1987) Expression of Xenopus N-CAM RNA is an early response of ectoderm to induction. Development 99:311325.

Krieg P, Varnum SM, Wormington WM, Melton DA (1989) The mRNA encoding elongation factor- $1 \alpha(\mathrm{EF}-1 \alpha)$ is a major transcript at the midblastula transition in Xenopus. Dev Biol 133:93-100.

Krotoski DM, Fraser SM, Bronner-Fraser M (1988) Mapping of neural crest pathways in Xenopus laevis using inter- and intra-specific cell markers. Dev Biol 127:119-132.

Lamborghini JE (1980) Rohon-Beard cells and other large neurons in Xenopus embryos originate during gastrulation. J Comp Neurol 189: 323-333.

Li M, Jan YN, Jan L (1992) Specification of the subunit assembly by the hydrophilic amino-terminal domain of the Shaker potassium channel. Science 257:1225-1230.

Lockery SR, Spitzer NC (1992) Reconstruction of action potential development from whole cell currents of differentiating spinal neurons. J Neurosci 12:2268-2287.

MacKinnon R, Yellen G (1990) Mutations affecting TEA blockade and ion permeation in voltage-activated $\mathrm{K}^{+}$channels. Science 250 : 276-279.

McFarlane S, Cooper E (1992) Postnatal development of voltage-gated $\mathrm{K}$ currents on rat sympathetic neurons. J Neurophysiol 67:12911300.

McKinnon D (1989) Isolation of a cDNA clone coding for a putative second potassium channel indicates the existence of a gene family. $\mathrm{J}$ Biol Chem 264:8230-8236.

Melton DA, Krieg PA, Rebagliati MR, Maniatis T, Zinn K, Green MR (1984) Efficient in vitro synthesis of biologically active RNA and RNA hybridization probes from plasmids containing a bacteriophage SP6 promoter. Nucleic Acids Res 12:7035-7056.

Moon RT, Christian JL (1989) Microinjection and expression of synthetic mRNAs in Xenopus embryos. Technique 1:76-89.
Nerbonne JM, Gurney AM (1989) Development of excitable mcmbrane properties in mammalian sympathetic neurons. J Neurosci 9:3272-3286.

Nieuwkoop PD, Faber J (1967) Normal table of Xenopus laevis (Daudin). Amsterdam North-Holland.

O'Dowd DK, Ribera AB, Spitzer NC (1988) Development of voltagedependent calcium, sodium and potassium currents in Xenopus spinal neurons. J Neurosci 8:792-805.

Perney TM, Marshall J, Martin KA, Hockfield S, Kaczmarek LK (1992) Expression of the mRNAs for the $\mathrm{K}_{\mathrm{v}} 3.1$ potassium channel gene in the adult and developing rat brain. J Neurophysiol 68:756-766.

Ribera AB (1990) A potassium channel gene is expressed at neural induction. Neuron 5:691-701.

Ribera AB, Spitzer NC (1989) A critical period of transcription required for differentiation of the action potential of spinal ncurons. Neuron 2:1055-1062.

Ribera AB, Spitzer NC (1990) Differentiation of $I_{K A}$ in amphibian spinal neurons. J Neurosci 10:1886-1891.

Ribera AB, Spitzer NC (1992) Developmental regulation of potassium channels and the impact on neuronal differentiation. In: Ion channels, Vol 3 (Narahashi T, ed), pp 1-38. New York: Plenum.

Rudy B, Kentros C, Weiser M, Fruhling D, Seredio P, Vega-Saenz de Miera E, Ellisman MH, Pollock JA, Baker H (1992) Region-specific expression of a $\mathrm{K}^{+}$channel gene in brain. Proc Natl Acad Sci USA 89:4603-4607.

Ruppersberg JP, Schroter KH, Sakmann B, Stocker M, Sewing S, Pongs O (1990) Heteromultimeric channels formed by rat brain potassium-channel proteins. Nature 345:535-537.

Sadaghiani B, Thiebaud CH (1987) Neural crest devclopment in the Xenopus laevis embryo, studied by interspecific transplantation and scanning electron microscopy. Dev Biol 124:91-110.

Sanger F, Miklen S, Coulson AR (1977) DNA sequencing with chainterminating inhibitors. Proc Natl Acad Sci USA 74:5463-5467.

Sheng M, Tsaur M-L, Jan YN, Jan LY (1992) Subcellular segregation of two A-type $\mathrm{K}^{+}$channel proteins in rat central neurons. Neuron 9:271-284

Spitzer NC, Lamborghini JE (1976) The development of the action potential mechanism of amphibian neurons isolated in cell culture. Proc Natl Acad Sci USA 73:1641-1645.

Strong M, Chandy KG, Gutman GA (1993) Molecular evolution of voltage-sensitive ion channel genes: on the origins of electrical excitability. Mol Biol Evol 10:221-242.

Stuhmer W, Ruppersberg JP, Schroter KH, Sakmann B, Stocker M, Giese KP, Perschke A, Baumann A, Pongs O (1989) Molecular basis of functional diversity of voltage-gated potassium channels in mammalian brain. EMBO J 8:3235-3244.

Swanson R, Marshall J, Smith JS, Williams JB, Boyle MB, Folander $\mathrm{K}$, Luneau CJ, Antanavage J, Oliva C, Buhrow SA, Bennett C, Stein RB, Kaczmarek LK (1990) Cloning and expression of cDNA and genomic clones encoding three delayed rectifier potassium channels in rat brain. Neuron 4:929-939.

Taylor JSH, Roberts A (1983) The early development of the primary sensory neurones in an amphibian embryo: a scanning electron microscope study. J Embryol Exp Morphol 75:49-66.

Tempel BL, Jan YN, Jan LY (1988) Cloning of a probable potassium channel gene from mouse brain. Nature 332:837-839.

Thompson SH (1977) Three pharmacologically distinct potassium currents in molluscan neurones. J Physiol (Lond) 265:465-488.

Tsaur M-L, Sheng M, Lowenstein DH, Jan YN, Jan LY (1992) Differential expression of $\mathrm{K}^{+}$channel mRNAs in the rat brain and downregulation in the hippocampus following seizures. Neuron 8:10551067.

Warner AE (1973) The electrical properties of the ectoderm in the amphibian embryo during induction and early development of the nervous system. J Physiol (Lond) 235:267-286.

Wu R-L, Barish ME (1992) Two pharmacologically and kinetically distinct transient potassium currents in cultured embryonic mouse hippocampal neurons. J Neurosci 12:2235-2246.

Yellen G, Jurman ME, Abramson T, MacKinnon R (1991) Mutations affecting internal TEA blockade identify the probable pore-forming rcgion of a $\mathrm{K}^{+}$channcl. Science 251:939-942.

Yool AJ, Schwartz TL (1991) Alteration of ionic selectivity of a $\mathrm{K}^{+}$ channel by mutation of the H5 region. Nature 349:700-704.

Zhong Y, Wu C-F (1991) Alteration of four identified $\mathrm{K}^{+}$currents in Drosophila muscle by mutations in eag. Science 252:1562-1564. 